\title{
Indole-3-Carbinol Inhibits Laryngeal Cancer Growth Through Cell Cycle Arrest
}

\author{
Chenggang Mao ${ }^{1, \dagger}$, Xiaochun Zhou ${ }^{1, *, \dagger}$, Yidao Jiang ${ }^{1}$, Lijia Wan $^{1}, Z_{\text {Zezhang Tao }}{ }^{2}$ \\ ${ }^{1}$ Department of Otolaryngology-Head and Neck Surgery, Jingzhou Central Hospital, The Second Clinical Medical College, Yangtze University, \\ Jingzhou, China \\ ${ }^{2}$ Department of Otolaryngology-Head and Neck Surgery, Renmin Hospital of Wuhan University, Wuhan, China
}

Email address:

mcg126@126.com (Xiaochun Zhou),22101163@qq.com (Yidao Jiang)

${ }^{*}$ Corresponding author

$\dagger$ Chenggang Mao and Xiaochun Zhou are co-first authors.

\section{To cite this article:}

Chenggang Mao, Xiaochun Zhou, Yidao Jiang, Lijia Wan, Zezhang Tao. Indole-3-Carbinol Inhibits Laryngeal Cancer Growth Through Cell Cycle Arrest. Journal of Diseases and Medicinal Plants. Vol. 5, No. 2, 2019, pp. 22-28. doi: 10.11648/j.jdmp.20190502.11

Received: March 21, 2019; Accepted: May 5, 2019 Published: June 4, 2019

\begin{abstract}
The growth of a variety of tumors are inhibited by indole-3-carbinol (I3C) obviously. But, its role in laryngeal cancer is not clear. The goal of this study was to research the probable roles that laryngeal cancer cell apoptosis and proliferation Hep-2 was influenced by I3C. I3C dose-dependently therapy obviously inhibited Hep-2cell proliferation, and, I3C promoted apoptosis and induced cell morphological changes at 100, 200, 300, $400 \mu \mathrm{M}$ doses. We discovered that I3C shows anticancer effect through various signal pathways after Hep-2 cells I3C therapy. In Hep-2laryngeal cancer cell line, through decreasing cell cycle-related proteins that include cyclin D1, CDK6, CDK4, and pRb, G1 arrest was induced by I3C. Apart from this, BALB/c nude mice constructed tumor-bearing mouse models. BALB/c nude mice were divided into three groups: treated with $\mathrm{I} 3 \mathrm{C}$, untreated control group and pretreated with $\mathrm{I3C}$. After 8 weeks treatment, the untreated control group developed bigger tumors compared to mice treated or pretreated with $\mathrm{I3C}$, and in the tumors such as cyclin D1, CDK6, CDK4 and $\mathrm{pRb}$ cell cycle-related proteins were obviously decreased. Further, the study result showed there was no harmful side effect in the heart, liver and kidney of the I3C-treated nude mice. In conclusion, both in vivo and in vitro I3C inhibited proliferation and induced the Hep-2 cells apoptosis, and showed low toxicity to normal cells. By suppressing the expression of cyclin families and $\mathrm{CDK}$, we deduce that $\mathrm{I} 3 \mathrm{C}$ can inhibit the Hep-2 cells growth in vitro. On normal organs and tissues, the I3C had no toxic effects and was safe.
\end{abstract}

Keywords: Laryngeal Cancer, Indole-3-carbinol, Cell Cycle, Apoptosis

\section{Introduction}

In the head and neck, in highly developed countries, laryngeal cancer which is one of the leading malignant tumors is reported to have a higher incidence [1]. There are many choices including the traditional ways of chemotherapy, radiotherapy and surgery that can be used to treat laryngeal cancer. But, it is known to all that the curative rate and effect is poor and demand obvious increasement. For treating laryngeal cancer, a less toxic and highly effective way is lacking, although for the cancer treatment, many chemotherapeutic drugs are available.

The beneficial effects of intake of fruits and vegetables have been shown in lowering the incidence of cancers in recent dietary and epidemiological studies. Indole-3-carbinol (I3C), which is a natural phytochemical the vegetables of the cruciferous family ingredient, by inducing apoptosis displays anticancer activity $[2,3]$ and cell cycle arrest [3, 5], showing antimetastatic properties [2,6] and suppressing angiogenesis gene products [7]. In some signal transduction pathways that were associated with the cell growth inhibition, the anticancer activity of $\mathrm{I3C}$ is also reflected. the inhibition effects of $\mathrm{I} 3 \mathrm{C}$ have been evaluated by previous studies on the PI3K/Akt pathway [2, 7, 8] and nuclear factor-kB [9] signal transduction pathways. And mitogen-activated protein kinases (MAPK) expression was also been down-regulated by $\mathrm{I} 3 \mathrm{C}$ 
[10].

The study showed the probable effects of I3C on cell cycle arrest induction in vitro in Hep-2 laryngeal cancer cells, and characterize involved in vitro the proteins. Furthermore, the therapeutic and preventive effects of I3C were evaluated by us in laryngeal cancer.

\section{Materials and Methods}

\subsection{Reagents}

From the Cancer Research Institute of Sun Yatsen University (Guangzhou, China), the Hep-2laryngeal cancer cell line and 16HBE human normal bronchial epithelial cell line were purchased [11-13] and in our laboratory conserved and in liquid nitrogen stored. Fetal bovine serum (HyClone, USA), RPMI 1640 medium, cell counting kit-8 (Dongji, Japan), Cyclin CDK4, CDK6, pRb, D1, Rb antibody and GAPDH antibody (Cell Signaling Technology, USA), $0.25 \%$ trypsin solution (Invitrogen, USA) were purchased from mentioned above companies.

\subsection{Cell Grouping and Culture}

The 16HBE human normal bronchial epithelial cell line and Hep-2 laryngeal cancer cell line were cultured in RPMI 1640, with $20 \mathrm{mg} / \mathrm{ml}$ ampicilin and kanamycin and $10 \%$ fetal bovine serum supplemented. In an incubator with $5 \% \mathrm{CO}_{2}$ at $37^{\circ} \mathrm{C}$, all the cells were maintained. In logarithmic growth phase, in the experiment cells were used. In DMSO, in the Hep-2 and 16HBE group, I3C diluted with $0 \mathrm{mM}, 100 \mathrm{mM}$, $200 \mathrm{mM}, 300 \mathrm{mM}, 400 \mathrm{mM}$ final concentration was added, and control group which uses the same vehicle.

\subsection{Cell Proliferation Assay}

In 96 well plates, $16 \mathrm{HBE}$ and Hep-2 cells were seeded withper well for normal culture $1 \times 10^{3}$ cells. With a final concentration mentioned above in the experimental groups I3C were added. In each group the experiments were done in duplicate for 3 times, and also a blank control was used. each well added into $10 \mathrm{ml}$ of CCK- 8 and incubated at $37^{\circ} \mathrm{C}$ for 1 hour after $0 \mathrm{~h}, 24 \mathrm{~h}, 48 \mathrm{~h}$ and $72 \mathrm{~h}$ culture, and at $450 \mathrm{~nm}$ the absorbance value was detected.

\subsection{For Detection of Cell-cycle Distribution Propidium Iodide Single Staining}

16HBE and Hep-2 cells were harvested by trypsinization and in each group the cells were washed twice with cold phosphate-buffered saline after with different concentrations of I3C mentioned above treatment for $48 \mathrm{~h}$. For overnight fixation $70 \%$ ethanol was used; in 500 ul PBS cells were resuspended after centrifugation. Then $20 \mathrm{ml} \mathrm{of} 1 \mathrm{mg} / \mathrm{ml}$ of RNase and $0.5 \%$ TritonX-100 were added. $5 \mathrm{ml}$ of $1 \mathrm{mg} / \mathrm{ml}$ propidium iodide (PI) solution was added after standing for $30 \mathrm{~min}$ at room temperature and at room for $30 \mathrm{~min}$ temperature incubated. On a FACStar (Becton-Dickinson, Mountain View, California, USA), then Flow cytometry analysis was performed to determine the cell-cycle distribution. For each sample approximately 10,000 cells were examined, and with CELLQuest software (BD Biosciences, USA) the data were analyzed.

\subsection{Western Blot}

In the buffer which containe $1 \%$ Nonidet-P40, protease inhibitor 'cocktail' (Roche) and $2 \mathrm{mM}$ dithiothreitol, the Hep-2 cells and in nude mice tumor xenograft were lysed and harvested. by $12 \%$ SDS-PAGE lysates were resolved, transferred to nitrocellulose membranes, and with primary antibodies against cyclin CDK4, CDK6, D1, Rb, pRb and GAPDH immunoblotted., proteins were detected with enhanced chemiluminescence (ECL) reagent, after immunoblotting with secondary antibodies.

\subsection{Animal Grouping and Feeding}

Beijing HuaFukang Biological Technology Co. Ltd. (HFK Bioscience, Beijing, China) purchased female BALB/C nude mice that were $4 \sim 6$ weeks old and prior to the experiment underwent adaptive feeding one week. Contained $0.5 \% \mathrm{I} 3 \mathrm{C}$ feed nude mice and Beijing HuaFukang Biological Technology Co. Ltd manufactured the conventional nude mice feed. As previously described, animal welfare and xenograft tumor inoculation were performed [14, 15]. The nude mice was divided into three groups and each group eight nude mice, which include the preventive treatment group (before the inoculation of laryngeal cancer Hep-2 cells with feed containing $0.5 \% \mathrm{I} 3 \mathrm{C}$ for two weeks nude mice fed), the treatment group (when laryngeal cancer cells were inoculated feed containing $0.5 \% \mathrm{I} 3 \mathrm{C}$ ) and the control group (with laryngeal cancer cells fed with inoculated and regular feed). The experiment duration was 8 weeks. After the inoculation of laryngeal cancer Hep-2 cells, for volume calculation and statistical analysis the xenograft tumors long and short diameter in 2, 4, 6, 8Week were measured. The following equation estimated tumor volume: volume $=1 / 2 * L^{*} \mathrm{~W}^{2}$, where $\mathrm{W}$ is width and $\mathrm{L}$ is length [16]. After inoculation eight weeks, sacrificed the animals and for further evaluation the xenograft tumors, the liver, heart and kidney were preserved. Ahe Animal Ethics Committee of Renmin Hospital of Wuhan University approved the study.

\subsection{Hematoxylin and Eosin Staining}

For 24 hours, formalin fixed the heart, liver and kidney that were the xenograft tumor specimens, which were for 3 hours respectively dehydrated by $70 \%, 80 \%, 90 \%$ ethanol, and then for 1 hours $100 \%$ ethanol I, for 2 hours $100 \%$ ethanol II and for 20 minutes vitrified by xylene I and xylene II. for 40 minutes in paraffin I and II after immersing, the specimens were sliced and embedded. As follows staining was performed: for 15 minutes hematoxylin staining, for 35 seconds decoloring hydrochloric acid alcohol solution, for 10 minutes eosin staining and for 40 seconds decoloring $90 \%$ ethanol. Then for mounting neutral balsam was used and under the microscope the section was observed and 
photographed.

\subsection{Statistical Analysis}

All values were expressed as mean \pm SEM. SPSS16.0 one-way ANOVA using the SPSS statistical software carried out statistical analyses. As statistically significant probability values $(P$-value $)<0.05$ were considered.

\section{Results}

\subsection{The Growth of Laryngeal Cancer Cells Were Inhibited by $I 3 C$}

Used CCK-8 method the experiment studied whether I3C could effectively inhibit the carcinoma cells proliferation. with I3C significantly treatment inhibited the Hep-2 cells proliferation (Figure 1A) in a time- and dose-dependent manner. After $72 \mathrm{~h}$ treatment when the final concentration of I3C reached $300 \mathrm{mM}$, both exceeded $60 \%$ the inhibition efficiency in Hep-2 cell line additionally; and when the concentration was $400 \mathrm{mM}$ it reached to about $90 \%$. Specially, the same experiments were performed in human bronchial epithelial cells $16 \mathrm{HBE}$, in order to explore I3C the effects on the division and proliferation of normal human cells and tissues, (Figure 1B). The study indicated that compared with laryngeal cancer cell line Hep-2on 16HBE cell I3C400 $\mathrm{mM}$ had much less inhibitory effect proliferation.

A

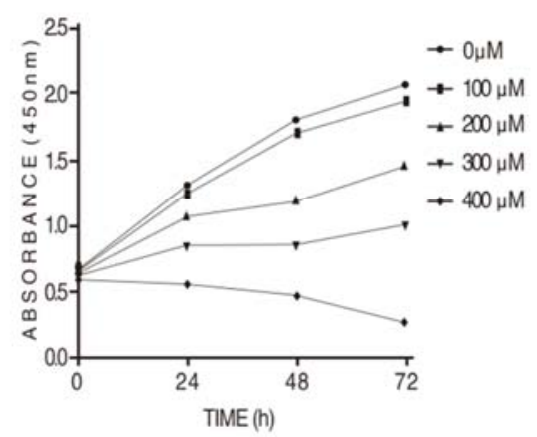

B

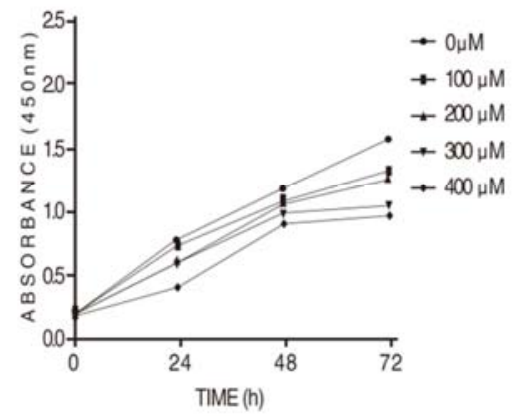

Figure 1. The viability of cells after $13 \mathrm{C}$ treatment. The viability of nasopharyngeal carcinoma cells Hep-2 and human bronchial epithelialcells 16HBE were detected by CCK-8 assay. (A) The proliferation of Hep-2 cells were inhibited by $I 3 C$ in a dose- and time-dependentmanner. (B) The proliferation of $16 \mathrm{HBE}$ cells were not inhibited by $\mathrm{I3C}$.

\subsection{In Laryngeal Cancer Cells I3C Induced Cell-Cycle Arrest}

To determine on cell cycle the I3C effect, after 48 hours treatment of $\mathrm{I} 3 \mathrm{C}$ with different concentrations using PI staining, the study evaluated the Hep-2 cells cell cycle distribution. The results indicated that after the treatment the laryngeal cancer cells cell cycle re-distributed. Significantly proportion of $\mathrm{G} 0 / \mathrm{G} 1$ phase cells increased, significantly proportion of $\mathrm{G} 2 / \mathrm{M}$ phase cells reduced and proportion of $\mathrm{S}$ phase cells had no significant change with the increase of I3C concentration. From $43.5 \%$ to $64.7 \%$ G0/G1phase cells increased, from $33.5 \%$ to $15.3 \% \mathrm{G} 2 / \mathrm{M}$ phase cells decreased, from $18.7 \%$ to $19.3 \% \mathrm{~S}$ phase cells differed in Hep-2 cells. (Figure 2A). But, in 16HBE cell line significantly each phase cells did not elevate when from 0 to $400 \mathrm{mM}$ the concentration of I3C changed (Figure 2B).

A.

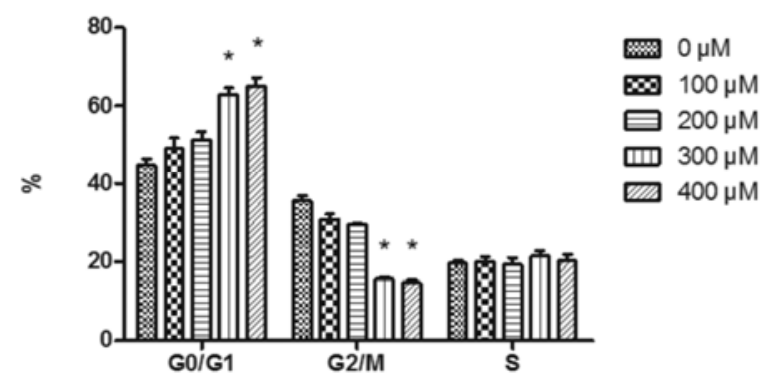

B.

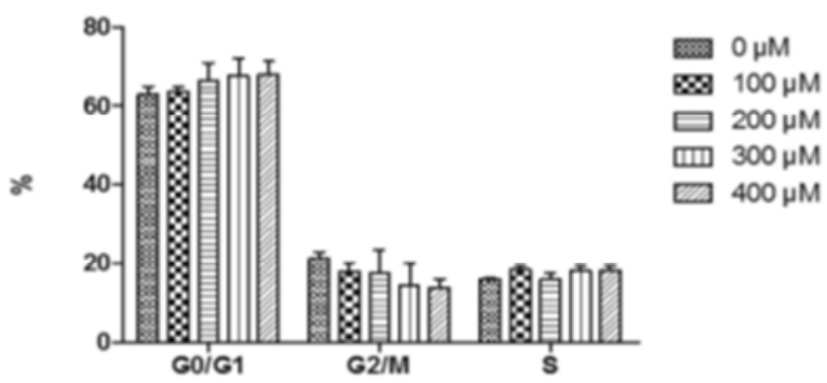

Figure 2. The result of cell cycle distribution. The cell cycle distribution was detected by flowcytometry. (A) The proportion of G0/G1 phase cells increased and $G 2 / M$ phase cells decreased in Hep-2 cell lines as $I 3 C$ concentration increased. (B) The proportion of all phase cells barely elevated in $16 \mathrm{HBE}$ cell line as I3C concentration increased. The data are presented as the mean \pm SEM. ${ }^{*} p<0.05$, compared to the proportion of each phase cells in 0 mM I3C treatment.

\subsection{After Treatment in Vivo and in Vitro I3C Changed the Expression of Cell Cycle Related Proteins}

In the cell cycle of laryngeal cancer cell lines, the study indicated above implicate that $\mathrm{I} 3 \mathrm{C}$ had a significant regulatory role. So, the study evaluated the several keyproteins expression involved in laryngeal cancer cells cell cycle regulation. We observed that cyclin CDK4, CDK6, D1 and $\mathrm{pRb}$ the protein expression levels were down-regulated as I3C concentration increased in Hep-2 cells (Figure 3). Additionally, in the nude mice Hep-2 xenograft tumors these 
proteins expression as compared to the control group from $\mathrm{I} 3 \mathrm{C}$ treatment and $\mathrm{I} 3 \mathrm{C}$ preventive groups decreased. (Figure 4)

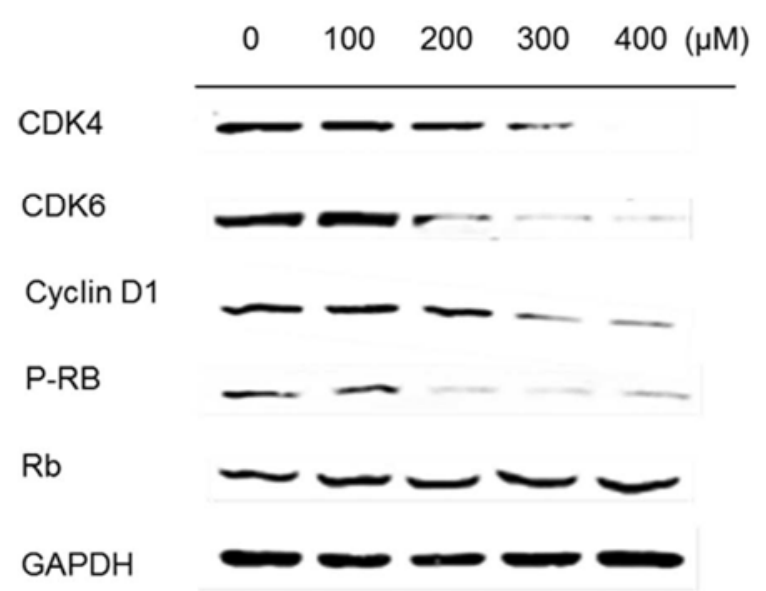

Figure 3. The expression of cell cycle related proteins in vitro. Key proteins related to cycle regulation were detected by WB. As I3C concentration increased, cyclin D1,CDK4,CDK6 and pRb protein expression in Hep-2 cell line were down-regulated. The data are presented as the mean $\pm S E M$.

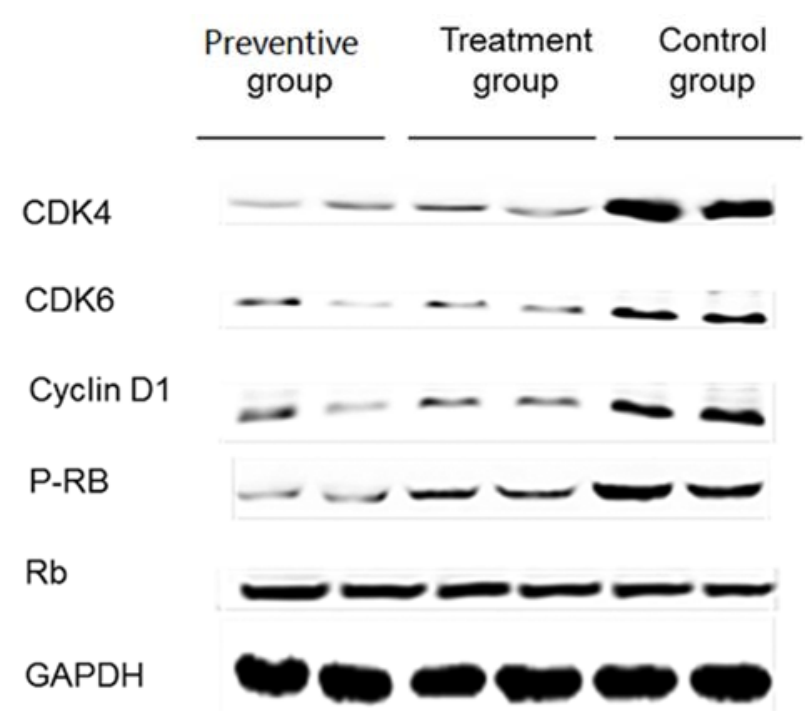

Figure 4. The expression of cell cycle related proteins in vivo. Cyclin D1, $C D K 4, C D K 6$ and $p R b$ protein expression were down-regulated in the xenograft tumors of Hep-2 in I3C preventive and I3C treatment groups compared to the control group. The data are presented as the mean $\pm S E M$.

\subsection{After Treatment in Vivo and in Vitro I3C Changed the Expression of NF-kBand MAPK Signaling}

Cells and xenograft tumors detected the NF-kBand MAPK proteins expression. when the I3C concentration increased, the Hep-2 cells down-regulated P-JNK, P-P38P-ERK1/2, and NF-kB (p65) (Figure 5). As compared to the control group, from I3C preventive and I3C treatment groups, in the nude mice xenograft tumors of Hep-2, these proteins expression also decreased (Figure 6).

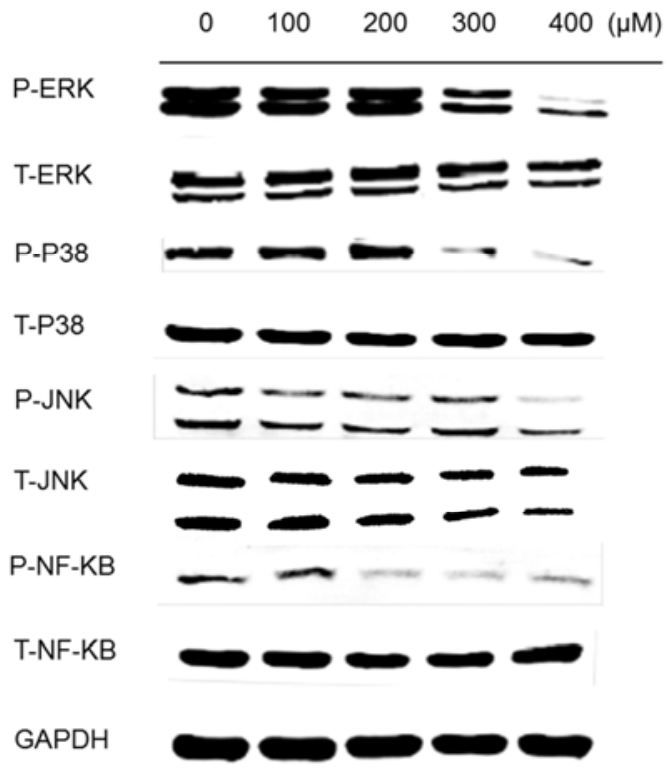

Figure 5. The expression of MAPK and $N F-k B$ proteins in vitro. The expression of MAPK and NF- $k B$ signaling decreased as $I 3 C$ concentrationincreased in Hep-2. The data are presented as the mean \pm SEM.

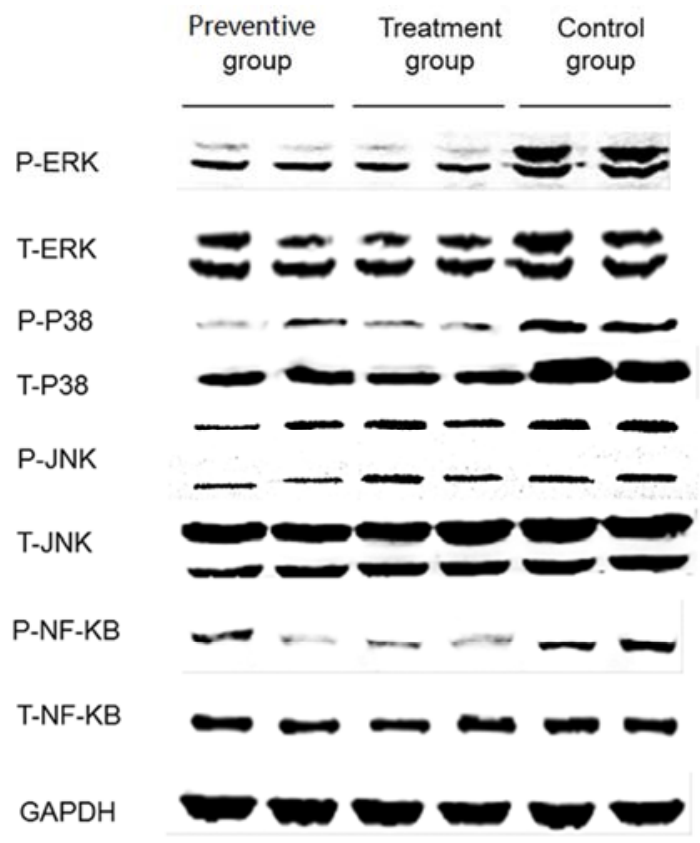

Figure 6. The expression of $M A P K$ and $N F-k B$ proteins in vivo. MAPK and $N F-k B$ proteins expression were down-regulated in the xenograftumors of Hep-2 in I3C preventive and I3C treatment groups compared to the control group. The data are presented as the mean \pm SEM.

\subsection{In Nude Mice Anti-tumor Efficacy of I3C}

In vivo animal experiments, the $\mathrm{I} 3 \mathrm{C}$ anti-tumor effects were studied. Rapidly in the control group the tumor volumes increased, and the control group was given only conventional nude mice feed. In the experiment 8 th week, the xenograft tumor mean volume in Hep-2 cellsof the nude mice control group, I3C treatment group and $\mathrm{I} 3 \mathrm{C}$ preventive treatment group were $(2596 \pm 478.37) \mathrm{mm}^{3},(1482 \pm 249.12) \mathrm{mm}^{3}$ and (802 \pm 225.32$) \mathrm{mm}^{3}$ (Figure7). 

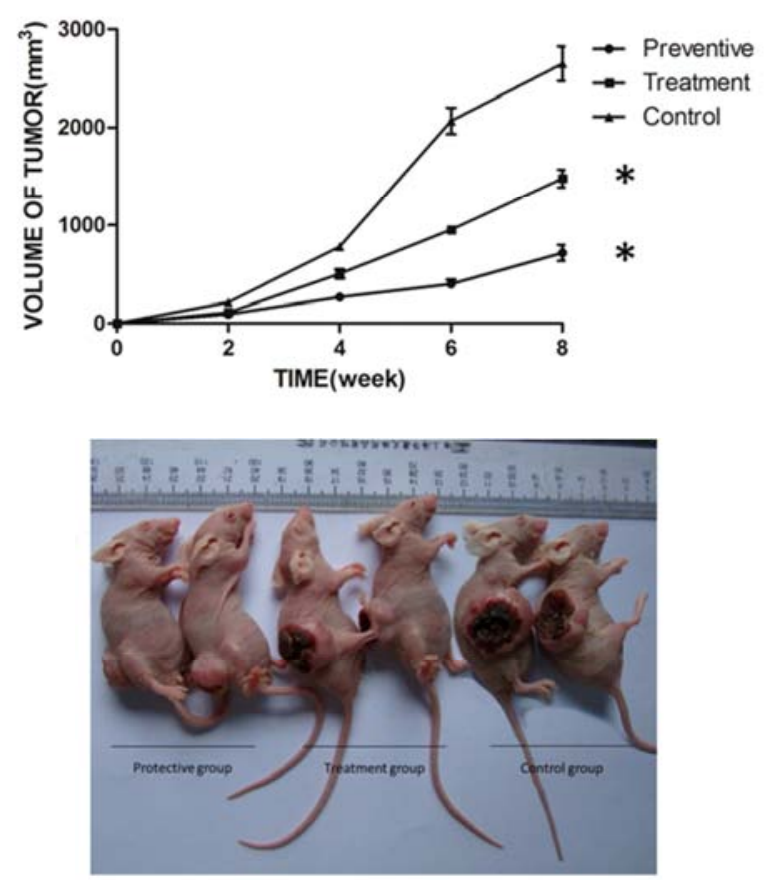

Figure 7. Anti-tumor efficacy of I3C in nude mice. The effect of I3C on tumor growth of Hep-2 in xenograft nude mice. The dataare presented as the mean $\pm S E M . * p<0.05$, compared to control group.

\subsection{As an Anti-tumor Agent Safety of I3C}

During treatments in order to evaluate whether I3C causes pathological damages to the experimental animals vital organs, the sections of the nude mice heart, liver and kidney routine HE staining in different groups was performed. In the heart, liver and kidney in all groups no necrosis, degeneration or structural disorders was observed, showing that the containing $0.5 \% \mathrm{I} 3 \mathrm{C}$ feed had on the heart, liver and kidney of the experimental animals no side or toxic effects (Figure $8)$.
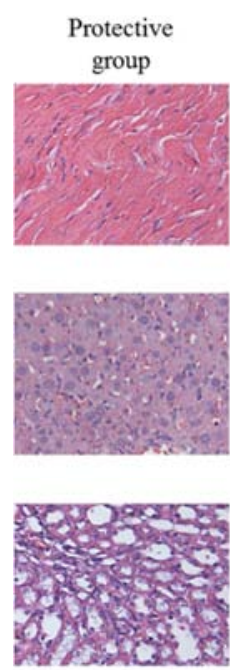

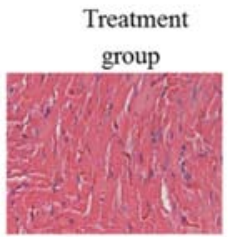

(A) Heart

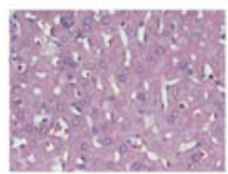

(B) Liver

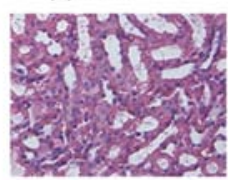

(C) Kidney
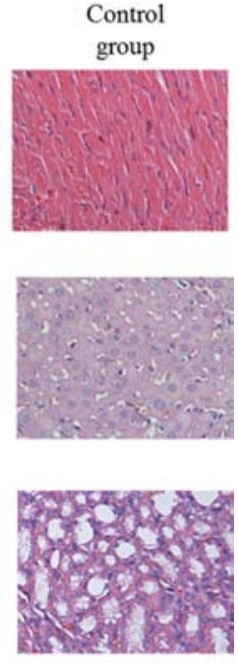

Figure 8. The result of $H E$ staining of main organs of nude mice after $13 C$ treatment. (A) HE staining of heart, (B) HE staining of liver, (C) HEstaining of kidney.

\section{Discussion}

In the laryngeal cancer treatment chemotherapy plays an important role. The high toxicity of the drugs being used is the current chemotherapy major problem [17]. So, laryngeal cancer chemotherapy needs drugs with improved efficacy and safety.

An active ingredient is $\mathrm{I} 3 \mathrm{C}$ which is extracted from natural cruciferous plants. In various tumor cells anti-tumor effect is showed by I3C significantly. In colon, prostate, lung and breast cancer cells cell cycle arrest is induced effectively. In laryngeal cancer the I3C studies were not sufficient. in vitro and in vivo in laryngeal cancer the study indicated the $\mathrm{I3C}$ effect in apoptosis [18, 19]. In this study, the Hep-2 human laryngeal cancer cell lines proliferation can be inhibited by I3C, but the 16HBE human normal bronchialepithelial cell line can not be inhibited by I3C. While exerting little effect on normal cells, this phenomenon indicated that $\mathrm{I} 3 \mathrm{C}$ suppressed the tumor cells growth in vitro. The study showed that I3C could specially inhibit the carcinoma cells proliferation and to normal cells I3C might be safe. Thus, as an anti-tumor drug $\mathrm{I} 3 \mathrm{C}$ which was used is promising.

From the previous studies [20-21], the study results showed that in the Hep-2 cell line G0/G1 cell cycle arrest was induced by $\mathrm{I} 3 \mathrm{C}$ and in vitro and in vivo the cyclin CDK4, CDK6, D1 and $\mathrm{pRb}$ downregulation in Hep-2 cells accompanied the arrest. The cell cycle regulation mechanism is the cyclins, CDKIs, and CDKs reciprocity. In cell cycle progression CDKs are the core effectors. CDK activity is regulated by inhibiting and activating the phosphorylation events and CDKIs as well as through the association with their cyclin partners. CDK $4 / 6$ phosphorylate $\mathrm{Rb}$ protein and cyclin $\mathrm{D}$ associated with CDK4/6. At the restriction point in G1 phase, they initiate progression. In mid-late G1 phase cyclin D/CDK4/6 activity occurs, and for the retinoblastoma gene product pRbhyperphosphorylation it is required. At the late G1 restriction point the protein $\mathrm{Rb}$ controls progression and the protein is the G1/S transition major regulator. Such as overexpression of related CDKs cyclin D, or mutations to CDKs, that affect $p 16$ binding, any component of this pathway alterations will lead to $\mathrm{Rb}$ phosphorylation and progression from phase G1 to S subsequently [22]. In many human tumors these alterations have been showed, which suggested that in their pathogenesis the cell cycle pathway inactivation can play an important role.

ERK1/2, JNK and p38 MAPK mediate MAPK signaling, and they are important in the cell differentiation, transformationand, proliferation control. Due to its transcriptional regulation, a transcriptional factor, NF-kB is critically involved in tumor progression [23]. Further, block apoptosis showed signaling pathway NF-kB, which by death receptors induced and promote cancer cells proliferation. In various tumor cells, NF-kB constitutive activation has been detected [24]. The study showed that through a MAPK pathway by cell cycle proteins transcriptional downregulation the cell cycle arrest observed may be regulated. Western blotting indicated that $\mathrm{I} 3 \mathrm{C}$ expression down-regulated the 
MAP kinase and NF-kB pathway several components in xenograft tumors and laryngeal cancer cells. Also I3C inhibits from $\mathrm{G} 1$ to $\mathrm{S}$ phase in vitro cell cycle progression and laryngeal cancer cell growth, and in vivo suppresses tumor formation of laryngeal cancer cell. The most likely mechanism that is underlying the $\mathrm{I} 3 \mathrm{C}$ induced growth arrest involves NF-kB and MAP kinases pathway down-regulation, which leads to in G1-related CDKs reduction, such as $\mathrm{p}-\mathrm{RB}$ and CDK4, and in CDK4 and cyclin D1 expression decrease [24].

In the experiment, in the preventive and treatment group containing $0.5 \%$ I3C normal diet was given. After the inoculation of tumor cells eight weeks, the tumor volume was the biggest in control group, moderate in treatment group and the smallest in I3C preventive treatment group. Thereby converting into several condensation products, studies indicated that $\mathrm{I} 3 \mathrm{C}$ is unstable in such as gastric juice acidic milieu. I3C exhibits such as anti-proliferative and pro-apoptotic against tumor or endothelial cells biological activities, but the effective concentrations of $\mathrm{I} 3 \mathrm{C}$ used in vitro in those experiments were relatively high (in most cases) $>100$ $\mathrm{mM}$ [25]. A previous study [26] detected I3C with $250 \mathrm{mg} / \mathrm{kg}$ I3C using an HPLC method following the dosing of mice in tissues. At $15 \mathrm{~min}$ the $28 \mathrm{mM} \mathrm{I3C}$ maximum level was observed. In mice and humans pharmacokinetic studies showed that in plasma the $\mathrm{I} 3 \mathrm{C}$ concentration within $1 \mathrm{~h}$ fell below the detection limit [27]. In the mice in preventive and treatment group the I3C average amount intake was close to $250 \mathrm{mg} / \mathrm{kg}$. It showed that in plasma the I3C concentration was approximate $28 \mathrm{mM}$. In much less than $300 \mathrm{mM}$ concentrations, I3C could inhibit in those two groups the xenograft tumor growth. It indicates that in vivo $\mathrm{I} 3 \mathrm{C}$ could inhibit the tumor growth effectively. The possibility is that metabolites are more active than against laryngeal cancer cells I3C in vivo. The studies have established that $400 \mathrm{mg} \mathrm{I3C}$ ingestion twice daily is tolerated well [28]. In the study, mice were with $\mathrm{I} 3 \mathrm{C}$ orally treated at about a $250 \mathrm{mg} / \mathrm{kg}$ per day dosage, which is equivalent to in an average adult human a $20.3 \mathrm{mg} / \mathrm{kg}$ dose [29]. Within the range in clinical trials the dose is that has been used. Moreover, since in this experiment the inoculated laryngeal cancer cells amount was large (approximately $2 \times 10^{6}$ ), it was not impossible to be prevented by $\mathrm{I} 3 \mathrm{C}$ completely. Due to mutation the tumor cells initial number in the human body was I3C small and stable blood plasma concentrations could destroy the mutated tumor cells majority, which might play an important role in the laryngeal cancer tumor prevention. In the prevention of laryngeal cancer tumor I3C could destroy the mutated tumor cells majority, which might play an important role.

\section{Conclusion}

The study indicated that I3C inhibited laryngeal cancer cell growth effectively. As a natural ingredient, to normal cells and tissues I3C caused little damage, and to use was relatively safe. The animal experiments results showed that I3C had certain tumor preventive effect and inhibited the tumors formation and development. In the future, it is important for us to focus on in recurrent laryngeal cancer the $\mathrm{I} 3 \mathrm{C}$ therapeutic effect.

\section{Acknowledgements}

The study was supported by grants from the Science and Technology Program of Jingzhou City (nos. 2017038 and 2017044).

\section{References}

[1] Jemal A, Bray F, Center MM, Ferlay J, Ward E, et al. (2011) Global cancer statistics. CA Cancer J Clin 61: 69-90.

[2] Chinni SR, Li Y, Upadhyay S, Koppolu PK, Sarkar FH (2001) Indole-3-carbinol (I3C) induced cell growth inhibition, G1 cell cycle arrest and apoptosis in prostate cancer cells. Oncogene 20: 2927-2936.

[3] Nachshon-Kedmi M, Yannai S, Haj A, Fares FA (2003) Indole-3-carbinol and 3,3'-diindolylmethane induce apoptosis in human prostate cancer cells. Food Chem Toxicol 41: 745-752.

[4] Hsu JC, Dev A, Wing A, Brew CT, Bjeldanes LF, et al. (2006) Indole-3-carbinol mediated cell cycle arrest of LNCaP human prostate cancer cells requires the induced production of activated p53 tumor suppressor protein. Biochem Pharmacol 72: $1714-1723$.

[5] Zhang J, Hsu BAJ, Kinseth BAM, Bjeldanes LF, Firestone GL (2003) Indole-3-carbinol induces a G1 cell cycle arrest and inhibits prostate-specific antigen production in human $\mathrm{LNCaP}$ prostate carcinoma cells. Cancer 98: 2511-2520.

[6] Takada Y, Andreeff M, Aggarwal BB (2005) Indole-3-carbinol suppresses NFkappaB and IkappaBalpha kinase activation, causing inhibition of expression of NF-kappaB-regulated antiapoptotic and metastatic gene products and enhancement of apoptosis in myeloid and leukemia cells. Blood 106: 641-649.

[7] Wu HT, Lin SH, Chen YH (2005) Inhibition of cell proliferation and in vitro markers of angiogenesis by indole-3-carbinol, a major indole metabolite present in cruciferous vegetables. J Agric Food Chem 53: 5164-5169.

[8] Aggarwal BB, Ichikawa H (2005) Molecular targets and anticancer potential of indole-3-carbinol and its derivatives. Cell Cycle 4: 1201-1215.

[9] Ping J, Gao AM, Qin HQ, Wei XN, Bai J, et al. (2011) Indole-3-carbinol enhances the resolution of rat liver fibrosis and stimulates hepatic stellate cell apoptosis by blocking the inhibitor of kappaB kinase alpha/inhibitor of kappaBalpha/nuclear factor-kappaB pathway. J Pharmacol Exp Ther 339: 694-703.

[10] Ping J, Li JT, Liao ZX, Shang L, Wang H (2011) Indole-3-carbinol inhibitshepatic stellate cells proliferation by blocking NADPH oxidase/reactive oxygenspecies/p38 MAPK pathway. Eur J Pharmacol 650: 656-662.

[11] Zhao P, Fu J, Yao B, Hu E, Song Y, et al. (2013) Diethyl sulfate-induced cell cycle arrest and apoptosis in human bronchial epithelial 16HBE cells. ChemBiolInteract 205: 8189. 
[12] Wu A, Luo W, Zhang Q, Yang Z, Zhang G, et al. (2013) Aldehydedehydrogenase 1 , a functional marker for identifying cancer stem cells inhuman nasopharyngeal carcinoma. Cancer Lett 330: 181-189.

[13] Yang Y, Liao Q, Wei F, Li X, Zhang W, et al. (2013) LPLUNC1 inhibits nasopharyngeal carcinoma cell growth via down-regulation of the MAP kinase and cyclin D1/E2F pathways. PLoS One 8: e62869.

[14] Han JB, Tao ZZ, Chen SM, Kong YG, Xiao BK (2011) Adenovirus-mediated transfer of tris-shRNAs induced apoptosis of nasopharyngeal carcinoma cell in vitro and in vivo. Cancer Lett 309: 162-169.

[15] Wang Y, Tao ZZ, Chen SM, Xiao BK, Zhou XH, et al. (2008) Application of combination of short hairpin RNA segments for silencing VEGF, TERT and Bcl-xl expression in laryngeal squamous carcinoma. Cancer Biol Ther 7: 896-901.

[16] Xie Y, Li Y, Peng X, Henderson F Jr, Deng L, et al. (2013) Ikappa B kinase alpha involvement in the development of nasopharyngeal carcinoma through aNF-kappaB-independent and ERK-dependent pathway. Oral Oncol.

[17] Ma BB, Chan AT (2005) Recent perspectives in the role of chemotherapy in the management of advanced nasopharyngeal carcinoma. Cancer 103: 22-31.

[18] Xu Y, Zhang J, Dong WG (2011) Indole-3-carbinol (I3C)-induced apoptosis in nasopharyngeal cancer cells through Fas/FasL and MAPK pathway. Med Oncol 28: 13431348 .

[19] Zhu W, Li W, Yang G, Zhang Q, Li M, et al. (2010) Indole-3-carbinol inhibits nasopharyngeal carcinoma. Int $\mathrm{J}$ Toxicol 29: 185-192.

[20] Liu DB, Hu GY, Long GX, Qiu H, Mei Q, et al. (2012) Celecoxib inducesapoptosis and cell-cycle arrest in nasopharyngeal carcinoma cell lines via inhibition of STAT3 phosphorylation. Acta Pharmacol Sin 33: 682-690.
[21] Ong CS, Zhou J, Ong CN, Shen HM (2010) Luteolin induces G1 arrest inhuman nasopharyngeal carcinoma cells via the Akt-GSK-3beta-Cyclin D1 pathway. Cancer Lett 298: 167-175.

[22] Paggi MG, Baldi A, Bonetto F, Giordano A (1996) Retinoblastoma protein family in cell cycle and cancer: a review. J Cell Biochem 62: 418-430.

[23] Aggarwal BB (2004) Nuclear factor-kappaB: the enemy within. Cancer Cell 6: 203-208.

[24] Orlowski RZ, Baldwin AS Jr (2002) NF-kappaB as a therapeutic target in cancer. Trends Mol Med 8: 385-389.

[25] Kim DS, Jeong YM, Moon SI, Kim SY, Kwon SB, et al. (2006) Indole-3-carbinol enhances ultraviolet B-induced apoptosis by sensitizing humanmelanoma cells. Cell Mol Life Sci 63: 26612668 .

[26] Anderton MJ, Jukes R, Lamb JH, Manson MM, Gescher A, et al. (2003) Liquid chromatographic assay for the simultaneous determination of indole-3-carbinol and its acid condensation products in plasma. J Chromatogr B Analyt Technol Biomed Life Sci 787: 281-291.

[27] Reed GA, Arneson DW, Putnam WC, Smith HJ, Gray JC, et al. (2006) Singledose and multiple-dose administration of indole-3-carbinol to women: pharmacokinetics based on 3,39-diindolylmethane. Cancer Epidemiol Biomarkers Prev 15: 2477-2481.

[28] Reed GA, Peterson KS, Smith HJ, Gray JC, Sullivan DK, et al. (2005) A phase Istudy of indole-3-carbinol in women: tolerability and effects. Cancer Epidemiol Biomarkers Prev 14: 1953-1960.

[29] Reagan-Shaw S, Nihal M, Ahmad N (2008) Dose translation from animal tohuman studies revisited. FASEB J 22: 659-661. 